\title{
DE SACRALE WERELD VAN DE TURKANA. RITUEEL, SYMBOOL EN MYTHE BIJ EEN NOMADENVOLK IN NOORDWEST KENYA.
}

\author{
Patrick WYMEERSCH ${ }^{+}$ \\ Patrick BERBEN
}

Boseind 33

B-3910 Neerpelt

Koen BOGERS

Hundelgemsesteenweg 910

B-9820 Merelbeke

\section{SUMMARY: THE SACRED WORLD OF THE TURKANA}

This article was mostly written by the late Patrick Wymeersch and was meant to be the onset to a broader monographical sketch of the religious world of the Turkana, a nomadic group of north-west Kenya. Attention is drawn to the organisation of the Turkana society and to several rituals which form the basis of the daily life environment. Furthermore the authors looked at the phenomena of the "Ngamoritunga" rocks and the position and the role of "Ang' $u$ ". One last word goes to the value of symbols within that society.

KEY WORDS: Turkana, religion, rituals, symbols. 


\section{INLEIDING}

Kenya telt ongeveer 35 etnische groepen die onder te brengen zijn in drie taalfamilies : de Bantoe, de Niloten en de Koeshieten.

Wat de economische en culturele overeenkomsten betreft zijn Niloten en Koeshieten eerder gericht op nomadisme en veeteelt, terwijl de Bantoe eerder landbouw verrichten.

Ongeveer een derde van de Kenyaanse bevolking is Niloot. Etnografisch behoren de Turkana van noordwest Kenya tot de Vlakte-Niloten, zoals de Maasai en de Pokot, hun zuidelijke buren. Het aantal Turkana wordt thans op ongeveer 250.000 geraamd.

De Turkanataal is nauw verwant met de talen van de naburige volkeren, zoals de Karamojong, de Jie, de Toposa en de Nyangatom. Zij wordt geclassificeerd als een Oostnilotische taal, een onderverdeling van de grote familie van Oostsoedanese talen die op hun beurt deel uitmaken van de Nilosaharische taalfamilie.

Volgens mondelinge overlevering, bevestigd door historisch onderzoek, zijn de Turkana ongever 300 jaar geleden vanuit het huidige noorden van Oeganda naar het zuiden getrokken en hebben zich dan gevestigd in de valleien rondom de Kagwalasi rivieren, een gebied gesitueerd in de Grote Slenk van Oost-Afrika, ten westen van het Turkanameer. Tijdens hun treken veroveringstocht verdreven de Turkana onder meer de Maasai naar zuidelijker gebieden.

De Turkana bewonen de schaars begroeide droge streken van noordwest Kenya : deels semi-woestijn, deels sterk geërodeerde lavavlakten met vulkanisch puin en rotsformaties.

De Turkana zijn nomadische veehouders, aan wie de veestapel niet alleen voedsel en bestaanszekerheid verschaft, maar ook sociaal aanzien en individueel prestige. Hun kuddes bestaan uit koeien, dromedarissen, geiten, schapen en ezels.

Dergelijke herderseconomie is wel uiterst kwetsbaar. Als het regenseizoen te laat komt is er voedselschaarste voor mens en dier; valt er onvoldoende regen of blijft het regenseizoen uit, zoals steeds vaker voorkomt, dan volgt massale veesterfte en hongersnood. 
Het vee verschaft voedsel in de vorm van melk en bloed en bij bijzondere gelegenheden of rituelen ook vlees. De Turkana volgen oude migratieroutes, waarbij zij na de regentijd de kuddes eerst weg van het betere, hoger gelegen land naar de drogere streken leiden voor het grazen van het schaarse jonge groen aldaar; wanneer het klimaat droger wordt keren de herders met hun kuddes terug naar de rijkere graslanden nabij rivieren of hellingen.

De Turkana kennen traditioneel geen vorm van centraal bestuur of gezag; er zijn dus geen zogenaamde stam- of dorpshoofden. Zaken van algemeen belang (zoals gebruik van waterputten, conflicten met buren, veerooftochten) worden behandeld op een vergadering van geïnitieerde mannen van een bepaald territorium dat men omschrijft als de 'adakar', dit is het gebied waar het vee van een aantal families gezamenlijk graast. Invloed en politieke macht worden voornamelijk bepaald door leeftijd en veebezit.

De kern van de Turkanamaatschappij is het gezin, in een dubbele betekenis. Enerzijds het kerngezin met de man, zijn vrouwen en hun respectievelijke kinderen. Anderszijds de uitgebreide familie, met andere woorden alle bloedof andere verwanten, die gewoonlijk ver van elkaar verblijven, als gevolg van de nomadische levenswijze. Het gezinshoofd - de familievader - is de absolute autoriteit, die beslist over de gang van zaken (vee, huwelijk, ritueel) binnen het gezin.

Door initiatie (het'asapan'-ritueel) wordt een jongen lid van een leeftijdsklasse. De Turkana kennen een systeem van twee alternerende leeftijdsklassen: de jachtluipaarden ('Ngirisai') en de Stenen ('Ngimor'). Een zoon wordt lid van de andere leeftijdsklasse dan deze waartoe zijn vader behoort. Een metalen ring ('alagama') in koper of ijzer door de vrouwen rond de hals gedragen illustreert de leeftijdsklasse waartoe haar echtgenoot behoort.

Het lidmaatschap van een leeftijdsklasse speelt een voorname rol in het sociale leven en legt een plicht op van wederzijdse solidariteit, hetgeen zich uit o.m. in het 'akipeyore"-ritueel (ritueel doden en nuttigen van een dier) of in de takkverdeling bij veeroof. De solidariteit van het gezin wordt met andere woorden doorkruist door een even sterke band, namelijk de solidariteit van de leeftijdsklasse. 


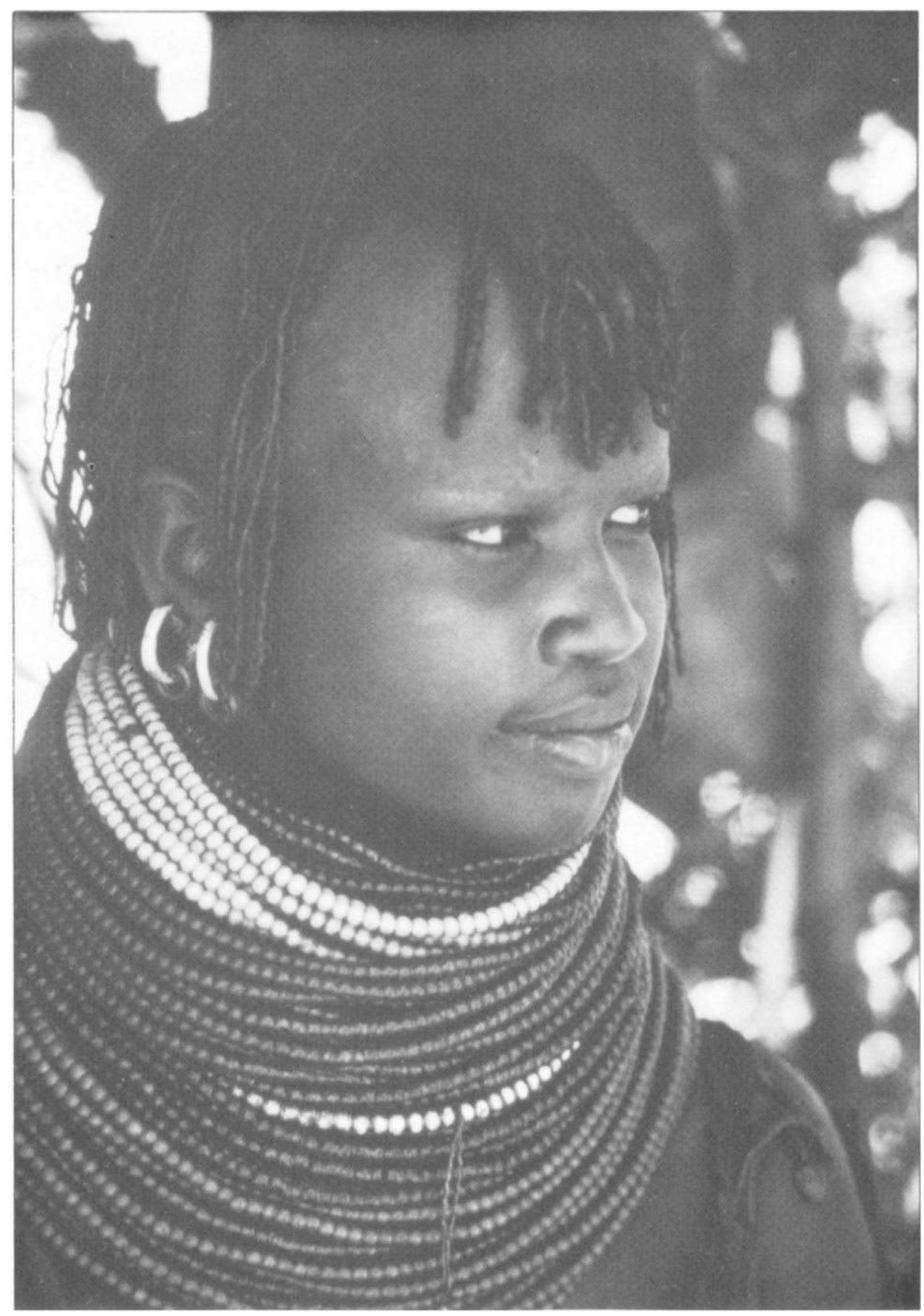

Jonge Turkana-vrouw, Kenya 1987

Foto: D.Beke 
Het woonerf ('awi') is de basiseenheid van het familiaal en economisch leven. De cirkelvormige omheining van doornige acaciatakken beveiligt de hutten en het vee tegen indringers. De omheining geldt tevens als een symbool van de onderlinge verbondenheid en afhankelijkheid van de mensen die er leven.

Binnen het woonerf staan de slaaphutten en dagverblijven van de gehuwde vrouwen; de familievader bezit zelf geen hut, maar eet en slaapt beurtelings bij een van zijn vrouwen. De materiële cultuur van de Turkana wordt gekenmerkt door een uitgesproken aandacht voor lichaamsversiering en door de vervaardiging van enkele typische gebruiksvoorwerpen. Men stelt een sterk vakmanschap vast, gepaard aan een zeldzame functionele verfijning van wat vervaardigd wordt uit hout, leder, zaden, metaal, schelpen, beenderen, ivoor, hoorn, hoeven, steen, pluimen en kalebassen.

De meisjes en vrouwen dragen veelkleurige kralensnoeren rond de hals en verder sierraden aan oren, in de haarvlechten en op de huiden die als rok of kleed worden aangewend. Typisch is ook de met kralen afgezoomde schaamschort.

Een belangrijke functie van kledij en sierraden is zeker het ten toon spreiden van de sociale positie van de draagster en het aanzien van haar man. Mannen lopen doorgaans naakt, enigszins versluierd door een rondgeslagen deken. Opvallend zijn de verzorgde kleikapsels van de krijgers en de oudere mannen bestaande uit een rode en grijze kleilaag en versierd met een struisvogelpluim. De houten neksteun ('ekicholong') is het teken van mannelijkheid en men zal nooit men een geïnitieerde Turkana ontmoeten zonder zijn neksteun, zijn polsmes ('abarait') en knuppel ('aburo'). Ook de lipplug wordt nog vaak aangebracht, zowel bij man als vrouw.

\section{HET ‘AKIPEYORE`-RITUEEL}

Tal van rituelen geven gestalte aan het dagelijse leven van de Turkana. Naargelang de beneficiant van het ritueel, kan men onderscheid maken tussen familie- of gemeenschapsrituelen. De eerste hebben betrekking op het welzijn van de familieleden van het woonerf en zijn meestal het ritueel doden van een dier, door het opensnijden van keel of buik. De tweede soort richt zich op het welzijn van de geïnitieerde mannen, en meer bepaald de mannen uit de 'adakar' (de buurt) en bestaat uit het doden van een offerdier met een speer. 


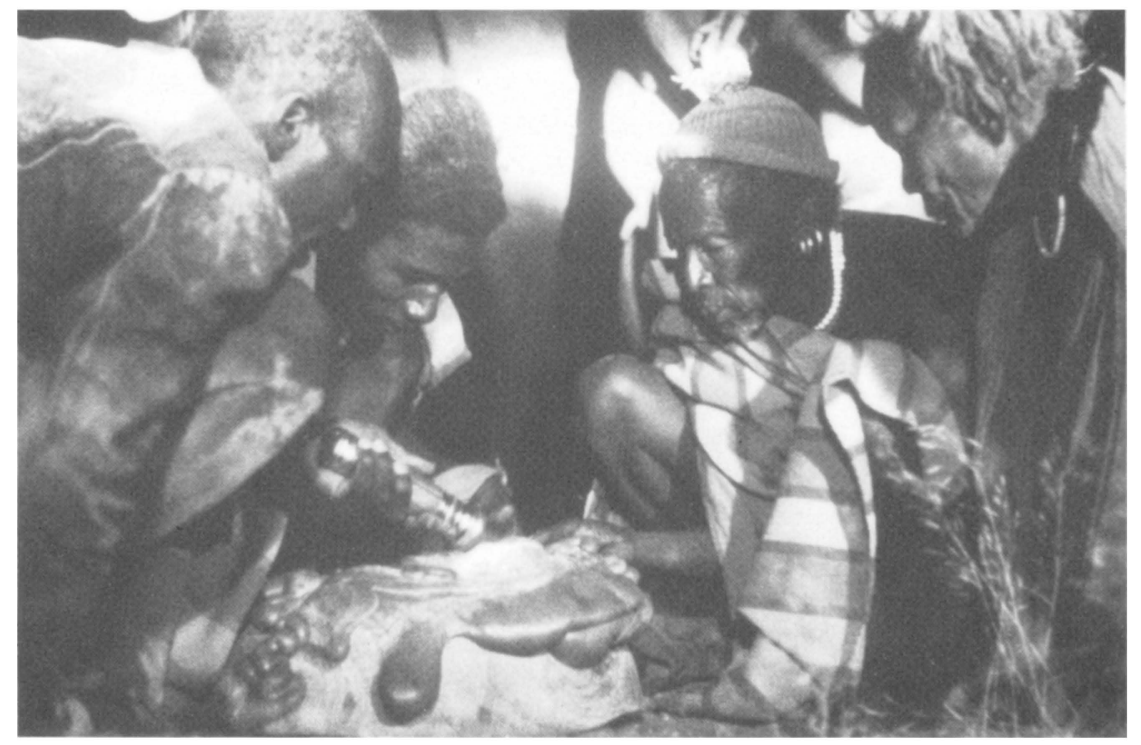

Het "lezen" van de ingewanden van het geslachte dier tijdens het 'akipeyore' ritueel; Kenya 1987

Foto: D.Beke 
De rituelen kunnen reinigend ('amook') van aard zijn, d.w.z. dat zij een bestaand of dreigend onheil dienen te bezweren of preventief ('ariwo') van aard zijn, dit wil zeggen dat zij pogen een gunstige sfeer tot stand te brengen en de kwade geesten in bedwang te houden.

Het belangrijkste collectieve ritueel bij de Turkana is de 'akipeyore'ceremonie, een strikt mannelijke aangelegenheid. Het Turkanawoord 'akipeyore' betekent : offeren aan, roosteren voor. Om een niet steeds aanwijsbare reden besluit een man een offerritueel uit te voeren ten behoeve van, in eerste instantie, de mannen van zijn leeftijdsklasse, doch voorts ook voor de geïnitieerden van de andere leeftijdsklasse. Het is dus een gemeenschappelijke maaltijd, een soort communio, van geïnitieerde mannen en de bijeenkomst biedt een goede gelegenheid om de relaties met de mannen van de buurt te onderhouden en gemeenschappelijke zaken te bespreken.

De initiatie heeft een minutieus, vast patroon : het doden van een mannelijk gecastreerd dier (meestal geit of schaap) met de patriarchale speer, het onderzoeken van de inhoud van de maag, het afschroeien van het haar, het slachten en snijden van het dier volgens de rituele regels, de verdeling van de stukken vlees, het gezamelijk nuttigen en tenslotte de verbale rite ('agata').

Een man kondigt aan een 'akipeyore" te houden, waarna de mannen uit de buurt met tussenpozen aankomen bij de sacrale boom ('elim') in de droge rivierbedding. Een dier wordt naar de slachtplaats geleid en gedood met één speerstoot, recht in het hart. Wanneer meedere speerstoten zouden nodig zijn, voelt de Turkana zich verstoord en zal een reinigend ritueel moeten worden uitgevoerd om het slecht voorteken te keren.

Als het dier na enige stuiptrekkingen dood is wordt het neergelegd - de buik naar het oosten gericht - op een strook verse groene bladeren, de eigenlijke slachtplaats ('ayenget') door de krijgers samengebracht. De jonge mannen van dienst snijden de buik open met het lemmet van de speer en nemen maag en ingewanden eruit.

De ingewanden worden bij de oudere mannen gebracht, die gehurkt in een halve cirkel zitten. De specialisten "lezen" de ingewanden, interpreteren de gegevens die hen worden voorgelegd en voorspellen de nabije toekomst. $\mathrm{Zij}$ situeren ziekte en droogte, voorspoed en onheil voor de komende dagen en mensen van de buurt zullen rekening houden met hun advies. Wanneer de mannen hierbij ongerust of opgewonden geraken zal men het ritueel 

onderbreken om hen letterlijk te laten afkoelen: de gastheer neemt water en besprenkelt de borst van de deelnemers. Individueel kan de Turkana zich ook reinigen door de borst in te wrijven met de maaginhoud ('ngikujit') van het geslachte dier. Al deze handelingen worden verricht terwijl het aangezicht naar het oosten is gekeerd.

Voor de ceremonie hebben de jonge mannen een offer- en zitplaats ('akiriket') gevormd, een halve cirkel van takken met groene bladeren en met de opening naar het oosten. De leden van de twee leeftijdsklassen nemen ieder één helft van de halve cirkel in beslag, de Stenen zitten aan de linkerkant van de Jachtluipaarden. De oudste van iedere leeftijdsklasse neemt plaats in het midden van de halve cirkel, geflankeerd door de andere leden van hun leeftijdsklasse, in volgorde van senioriteit.

Terwijl de mannen in de halve cirkel zitten, wordt de maaginhoud naast de slachtplaats uitgestort. De maaginhoud wordt beschouwd als het voedsel voor God ('Akuj') en de geesten ('ngipian') die de wereld bewonen. Waarna men het dier naar de vuurplaats ('ekeno") draagt, de haren ervan afschroeit en het terug naar de slachtplaats brengt.

Vervolgens wordt het dier met een polsmes versneden: eerst snijdt men het deel tussen de staart en de testikels ('elamacar'), daarna snijdt men het vlees van de lenden ('nga-polia') en ook de overige delen in welbepaalde volgorde. Terwijl enkele krijgers het bloed uit het karkas opdrinken, wordt het vlees geroosterd.

Eerst wordt aan de mannen de dunne darm, de maag en de lever aangeboden, nadien komt het echte vlees. De gastheer die het dier aangeboden heeft komt naar de slachtplaats om de rechterachterpoot ('amuro nakitalio') af te snijden. De oudste man van het gezelschap zal dit stuk meenemen naar zijn erf.

Als de ceremonie, die uren kan duren, beëindigd is, richt de priestermedicijnman ('emuron') zich op, neemt de speer en verricht een verbale rite ('agata') die de 'akipeyore" afsluit. Hij wijst daarbij naar het westen, waar de voorouders wonen, spreekt over de heldendaden van het verleden en roept om heil voor de toekomst. Zijn toespraak wordt in koor beaamd door alle aanwezigen. 


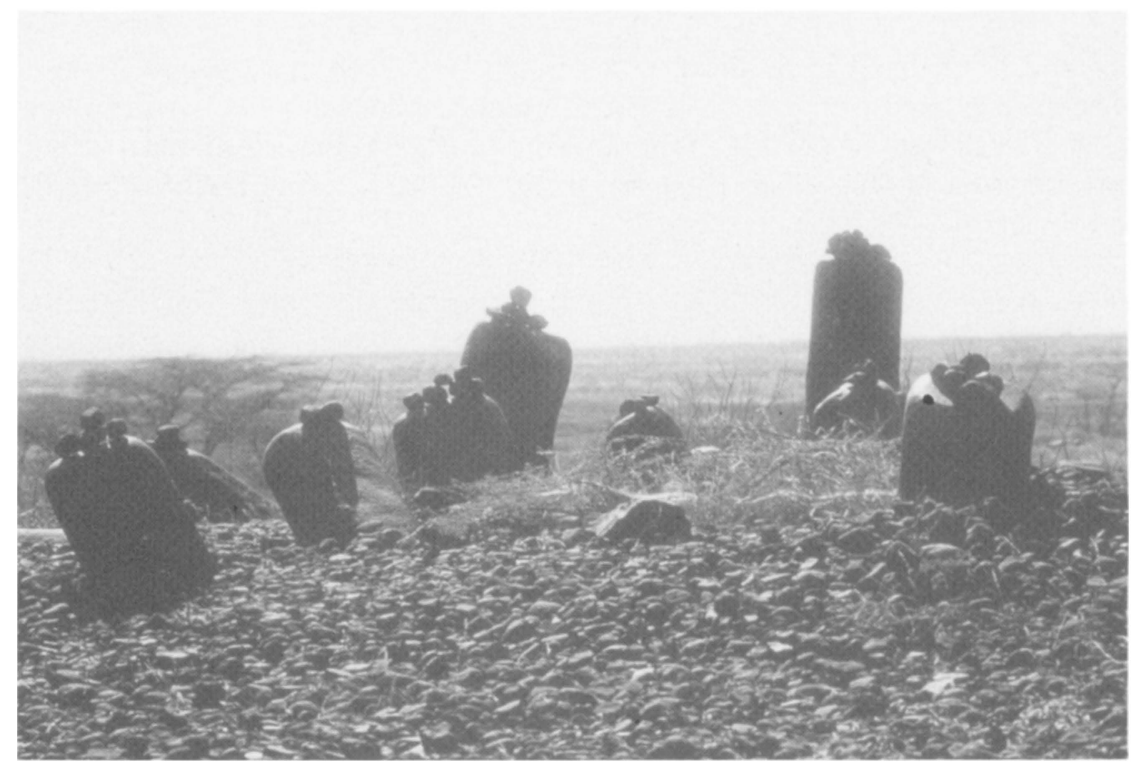

Een deel van de 'ngamoritunga' of monolitische site met negentien zuilen in basalt nabij Kalokol; Kenya 1987

Foto: D.Beke 


\section{HET RAADSEL VAN DE 'NGAMORITUNGA'}

Niet ver van Kalokol, aan het Turkanameer, vlak bij de weg naar Lodwar, bevindt zich een mysterieuze en indrukwekkende monolitische site bestaande uit 19 basaltstenen zuilen. Het geheel bestaat voorts uit vermoedelijk 2 of 3 graven, afgeboord door een cirkelvormige structuur van grote stenen.De zuilen zijn polygonaal, met een breedte van 25 tot $50 \mathrm{~cm}$; de hoogste zuil meet boven de grond $155 \mathrm{~cm}$. Sommige zuilen, die een mooi glanzende patina hebben, vertonen tal van steengraveringen. Rond de zuilen liggen hopen kleine stenen, die de voorbijtrekkende Turkana tot vandaag op de top van de zuilen leggen om het kwade af te wenden. Een ritueel dat ook wordt uitvoerd, telkens een Turkana op zijn migraties een graf, gevormd door enige grote stenen, passeert.

Tot op heden werd er nog geen C 14-datering uitgevoerd, maar wetenschapslui zijn van oordeel dat het monolitisch complex gebouwd werd in de 4de eeuw v.C. Hypothesen zijn er voldoende. De site zou een astronomisch centrum geweest zijn voor de berekening van een jaarlijkse kalender van 354 dagen en zou in verband moeten gebracht worden met de volkeren die een Oostkoeshietische taal spraken en afkomstig waren uit het zuiden van het huidige Ethiopië. Archo-astronomen beweren inderdaad dat de schuine opstelling van de zuilen zou correleren met wat de stand was van 7 sterren en de constellatie weergaven van deze sterren tot de maan.

De onderzoekers weten niet met zekerheid of de graven door de bouwers van het zuilencomplex zijn gemaakt. In feite zouden het ook recentere Turkanagraven kunnen zijn, want ook de Turkana begraven hun doden onder een tumulus van stenen. Aangezien de Turkana nauwelijks 300 jaren geleden naar hun huidige territorium zijn afgezakt, staat alleszins vast dat de zuilengraveringen zelf niet door hen zijn aangebracht, temeer dat de patina veel ouder is. Moeten deze graveringen en tekens toegeschreven worden aan de bouwers van de site ? Wel stelt men vast dat de huidige Turkana hun dieren merken met een aantal motieven van deze petroglyfen. Men heeft vastgesteld dat van de 99 waargenomen markeringen er 63 terug te vinden zijn op de zuilen. De vraag is dan ook of de Turkana deze tekens veel later zijn gaan copiëren, of dat integendeel de veemarkeringen zeer oud zijn en teruggebracht kunnen worden tot een gemeenschappelijke culturele kern, ver terug in de tijd ? Hierbij rijst de vraag of er een culturele uitwisseling bestond tussen Niloten en Koeshieten? 
In ieder geval kan men thans vaststellen dat de Turkana een groot aantal van deze tekens "onthouden" hebben, terwijl andere, pastorale volken ze "vergeten" zijn, want er is - evenwel voorlopig zonder grondig onderzoek niets dergelijks meer terug te vinden bij de Oost-Koeshieten. Daarentegen bezigen ook de Maasai, Pokot en Samburu, allen Niloten, deze tekens.

De vraagt blijft: wie waren de bouwers van deze unieke site? Een megalitische cultuur van Oost-Koeshieten? Kan de vergelijkende taalkunde de sluier van het mysterie lichten? Tot op heden zijn er echter geen sporen gevonden van Oostkoeshietische talen, ten westen van het Turkanameer. Zouden de Oostkoeshietischsprekende volken ooit dit gebied bewoond hebben, voordat ze verdrongen werden door de zogenaamde "Pottenbakkers van de Turkwei", een Oostnilotische cultuur van rond 450 v.C.? Mogelijks waren deze laatsen de bouwers van de site.

Als aanvaard wordt dat de bouwers Oost-Koeshieten zouden zijn, is het toch opmerkelijk dat ten oosten van het meer dergelijke monolitische sites ontbreken. Nochtans is daar de anwezigheid tijdens het tweede millenium v.C. van Oost-Koeshieten een vaststaand feit.... En in het gebied rond de site werden wel potscherven gevonden van Zuid-Koeshieten (2.000 v.C.) doch nooit van Oost-Koeshieten. Anderzijds menen onderzoekers dat de praktijk van de visvangst en de vistechnieken langs de westelijke oever van het Turkanameer teruggaat op een Oostkoeshietische oorsprong hebben na de verdringing van het traditionele visvangst- en visconsumptietaboe van de Oost-Niloten. Het geheel blijft een raadsel.

\section{HET TURKANAMONSTER : ANG'U}

Het dierenverhaal komt veelvuldig voor in de Afrikaanse traditionele cultuur. De Turkana-overlevering kent een beangstigend verhaal over Ang'u, het monster, dat zou leven in de rotsen van Lapur, maar vooral ronddwaalt in de gevoels- en ervaringswereld van de Turkana.

Op basis van veldonderzoek in 1986 is de voorzichtige conclusie dat het dier waarschijnlijk niet (meer) bestaat en zelfs geen uitgestorven soort is die in het collectieve bewustzijn van de Turkana verder leeft, doch eerder als een mythisch dier moet worden beschouwd. Deze mythe functioneert hier als een soort geactualiseerde vertolker en versterker van sociale waarden: het betreft een mythisch dier dat een welbepaalde functie vervult in de nomadische 
Turkana-maatschappij en waarvan het bestaan en handelen voortdurend levendig wordt gehouden en bevestigd wordt door ervaringen van zinsbegoocheling, illusie of hallucinatie van de individuele Turkana.

Overigens komt de gesublimeerde beschrijving van het monster in grote trekken overeen met dat van het reuze-schubdier (pangolin), een dier dat in vele Afrikaanse verhalen ten tonele wordt gevoerd en mogelijks ook aan de creatie van deze mythe ten grondslag ligt. Men stelt bijvoorbeeld vast dat het woord Ang'u etymologisch verwant is aan de zuidelijke Luo-taal, waar het "prooidier" betekent. Deze taal wordt gesproken in het zuidelijk Luo gebied, in Oeganda en Zaïre, waar precies de pangolin veel voorkomt.

Ang'u is een mensetend dier, dat in holen woont, hoog in de bergwand; het loopt op drie poten en richt zich op wanneer het mensen aanvalt; het heeft een lange staart, de kop van een dromedaris, de snuit van een wilde hond, oren als een konijn, tanden als een hondskopaap, het lijf van een hyena, klauwen met sporen als een kinderhand en volgens sommigen een buidel waarin het kleine kinderen kan vervoeren. Het jaagt 's nachts, verplaatst zich in de schaduw en valt langs achter aan, bij voorkeur eerst aan het hoofd en de schedel. Alleenwandelende Turkanavrouwen zullen dan ook vaak een steen op het hoofd dragen met daarop een omgekeerde kookpot, als bescherming tegen een onverhoedse aanval van Ang'u. Ang'u heeft een harde, onkwetsbare en een zachte, kwetsbare flank. Hij valt bij voorkeur 's nachts aan en heeft het vooral gemunt op alleenwandelende personen, op slecht geklede vrouwen, op vervelende kinderen, op loslopend vee.

Ang'u, of beter de Ang'u-mythe, functioneert verschillend in verscheidene fasen van het Turkana-leven. Lastige, kleine kinderen worden bang gemaakt en tot rust gedwongen met verhalen over Ang'u, waarbij dan iemand buiten een hut, een hol, jankend geluid produceert met behulp van een omgekeerd houten vat, een soort strijkstok en een gebogen vinger als "snaar". In een volgende fase groeit het verhaal mee met de kinderen, naar volwasenheid; het wordt een zaak van moed en durf Ang'u gehoord, gezien of ontmoet te hebben en het individueel aanzien wordt erdoor verhoogd.

De ontmoeting met Ang'u moet ook gezien worden als een transformatieproces van de initiandus: hij is niet meer wie hij was en nog niet wie hij zal zijn; een ambiguë toestand. Zulks wordt overigens geillustreerd en geaccentueerd door de dualistische karakteristieken tussen de menselijke eigenschappen van Ang'u (rechtopstaand, kinderhandsporen, geluid als een kind, kan mensen wegvoeren, kan op dak klimmen of op deur kloppen, 
zachte kwetsbare flank) en de dierlijke kenmerken (kop van een dromedaris, tanden van een baviaan, lijf van een hyena, woont in holen, leeft 's nachts, harde onkwetsbare flank).

Voorts is er een grote tegenstelling tussen de wereld en de normen die met Ang'u geassocieerd worden en de wereld en de waarden van de Turkana. Dit toont zich op velerlei vlakken: Ang'u leeft hoog in de bergen dichtbij de 'ngipian' (geesten), terwijl de Turkana in de vlakten en valleien wonen; Ang'u jaagt 's nachts, terwijl het Turkanaleven 's nachts stilvalt en men bescherming zoekt in de 'awi'; Ang'u valt de alleenwandelende Turkana aan, terwijl een Turkana steeds collectief handelt en de zich isolerende Turkana als het ware gestraft worden, Ang'u rooft soms vee, waardoor de nalatige hoeder gestraft wordt en voor de eigenaar van het vee voor het verlies een aanvaardbare en verschoonbare uitleg heeft; Ang'u valt slecht geklede vrouwen aan, waardoor het behoorlijk gedrag der vrouwen wordt geconformeerd en bestendigd, hetgeen overigens ook voor de kinderen geldt; Ang'u incarneert het kwade, al hetgeen van buiten de 'awi' komt, hetgeen contrasteert met de 'awi' in de betekenis van beveiligend gezin en woonerf.

Voormelde tegenstelling wordt in de mythe-analyse omschreven als de klassieke structurele oppositie tussen natuur en cultuur.

Ang'u komt uit al het voorgaande te voorschijn als diegene die de persoon zal straffen die de sociale gedragsregels binnen de Turkana-maatschappij verbreekt of tracht te verbreken. Hij versterkt op deze wijze cultureelvastgelegde waarden, in de Turkana-maatschappij terug te brengen tot het allesomvattend belang van het woonerf, de 'awi', het vaderlijk gezag over vrouwen, kinderen, vee en rituelen. Een bijkomende verklaring voor het levendig, bijna theatraal aanwezig zijn van Ang'u in het dagelijks leven van de Turkana kan gevonden worden in een meer psychologische verklaring van de mythe: de ervaringen met Ang'u komen voort uit hetgeen de psychologie zinsbegoocheling, illusie en hallucinatie noemt, ontstaan uit projecties van een volk dat leeft in zeer ruige omstandigheden inzake milieu, watervoorziening en klimaat en voorts in een extreme isolatie tegenover de buitenwereld en zelfs tegenover elkaar, gelet op het nomadisch bestaan. Verder dient men te weten dat de Turkana zuivere veenomaden zijn met een zekere afkeer voor wilde dieren, derwijze dat zij niet jagen en ook geen eigenlijke jachttechniek bezitten en daardoor in het wilde dier, bestaand of ingebeeld, een spiegel zien voor projecties. 


\section{TURKANA-SYMBOLIEK}

De Turkana bezitten veelvuldig rituele symbolen. Eénzelfde symbool kan bovendien verschillende betekenissen hebben, afhankelijk van de context waarin het wordt gehanteerd.

Zo heeft men bv. het symbool 'ngikujit' (maaginhoud) verscheidene betekenissen, onder meer een gunstige betekenis in een zogenaamd reinigende situatie ('amook'), wanneer het de mensen koel maakt en behoedt voor dreigend onheil. Het aanbrengen van de maaginhoud van een ritueel geslacht dier op het lichaam betekent eigenlijk het aanbrengen van een beschermende laag, tussen geesten en mens.

Ook het insmeren met 'emunyen' (natte klei) is eenzelfde beschermrite. Het woord "emunyen" wordt trouwens als synoniem gebruikt voor 'ngikujit".

Wanneer men de Turkana vraagt wáárom hij zich pleegt in te smeren met maaginhoud, zal hij antwoorden : "Wat is 'emunyen' ? Het is 'ngalup', aarde. Alles gaat naar de aarde, alles komt van de aarde. De aarde eet alles". De aarde is dus de kracht die het kwade neutraliseert. Alles wat het dier eet komt van de aarde en gaat naar de maag. De maag is dus als de aarde, de schoot waarheen alles terugkeert. 'Ngikujit' en 'emunyen' zijn verblijfplaatsen en eveneens voedsel voor de 'ngipian' (geesten) en 'Akuj' (God).

'Akuj' is alles wat een positieve betekenis heeft; heeft hetzelfde begrip een negatieve betekenis, dan is het 'ngipian'. Zo zijn de langverwachte eerste regenwolken 'Akuj'; de langdurige regens die overstroming en verwoesting brengen, of het vee verdrinken, zijn 'ngipian". 


\section{IK DOODDE ANG'U}

Ik heb Ang'u met mijn eigen ogen gezien. Verstomd stond ik te kijken naar zijn kleur, lengte, muil, oren, staart en poten en dan schoot ik hem neer met één kogel. Ik stapte naar het dode dier en zag eigenlijk niet zoveel verschil met een ander dier, behalve dat het vier oren had. Het had vier even grote poten; nooit had iemand mij verteld dat Ang'u hier vertoefde. Ik keerde het dode dier om het beter te kunnen observeren en zag de harde kant. Ang'u heeft een heel eigen manier om zijn mensenprooi te vangen. Eenmaal hij zijn prooi bemerkt kan hij geluid maken als een jonge dromedaris of als een gekke vrouw. Ang'u doolt en heeft geen vaste verblijfplaats. Hij rust overdag en gaat 's nachts op jacht. Hij verkiest menselijke wezens als voedsel. Hij valt mensen aan. Hij heeft een lange muil met ongeveer tweehonderd tanden en heeft geen haren.

Taana Logiel, $45 \mathrm{j}$,

Rukruk (1986)

\section{BEKNOPTE BIBLIOGRAFIE}

Wymeersch P., Berben P., Bogers K., 1987. In search of the Turkana monster. ANG'U or the reinforcement of social values. A hypothesis. Afrikanistische Arbeits Papiere, Köln 9:51-76.

Dimmendaal G., 1982. The Turkana Language. Dordrecht : Foris Publications.

Hauge H., 1986. Turkana Religion and Folklore. Stockholm : University of Stockholm.

Jagt K.van der., 1989. Symbolic Structures in Turkana Religions. Assen : Van Gorcum.

Wymeersch P., 1988. Turkana Cattle Classification. Some preliminary notes. A. A. P., Köln 16: 123-148.

Wymeersch P. en Berben P., 1986. The homestead of Nakoro. A.A.P., Köln 5 : 97-120. 